\title{
Uterinas com prazer
}

Uterines with Pleasure Uterinas con placer

Patrícia Lessa' (i) 0000-0002-8942-1308

'Universidade Estadual de Maringá, Departamento de Fundamentos da Educação, Maringá, PR, Brasil.87080-127 - sec-dfe@uem.br

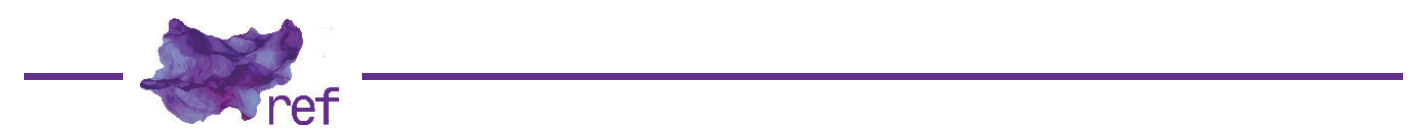

RODRIGÁÑEZ BUSTOS, Casilda.

Pariremos com prazer.

Trad. de Caroline Caires Coelho. Belo Horizonte: Editora Luas, 2020, 127p.

Casilda Rodrigañez Bustos nasceu na cidade de Madrid na Espanha, em 16 de maio de 1945. bióloga, escritora e feminista, em seus livros ela abordou questões sobre o corpo das mulheres, o parto, a maternidade, as culturas pré-patriarcais, a análise crítica do patriarcado relacionando a desconexão das mulheres com seus corpos, entre outros assuntos dessa natureza. No Brasil, dois de seus livros foram publicados pela Editora Luas: A Matrística: aqui e agora e o livro resenhado. Dentre suas obras, escreveu El asalto al Hades, La sexualidad y el funcionamiento de la dominación, La Represión del deseo materno y la génesis del estado de sumisión inconsciente, além de vários artigos e ensaios - todos estes ainda sem tradução para o português brasileiro. Os originais desses textos encontram-se disponíveis no site da autora: https:// sites.google.com/site/casildarodriganez/.

Pariremos com prazer aborda positivamente o útero como potência de vida, reconectando-o ao prazer e anunciando os meandros da invenção do parto com dor. O livro engloba as discussões: "Pariremos com prazer", "Parto orgásmico: testemunho de mulher e explicação fisiológica" e "Estender a teia". Na primeira parte do livro, "Pariremos com prazer", Casilda apresenta a tese do parto com prazer e a renúncia à dor no parto como significado de reapropriação feminista do poder fisiológico do útero descontraído e exercitado para o orgasmo. Em "Parto orgásmico: testemunho de mulher e explicação fisiológica", analisa a capacidade autoerótica das mulheres nos antigos rituais voltados para o exercício uterino e a preparação para o parto natural. Ela analisa, em imagens artísticas, a aparição destes rituais. E, finalmente, "Estender a teia" aborda a reconquista e o reaprendizado dos movimentos uterinos, tais como sentir sua pulsação e cadenciar seu fluxo em todo o corpo para recuperar a maternidade como local de afeto e de empoderamento. Para apresentar a tradução, a Editora Luas convidou a ginecologista feminista Halana Faria e a terapeuta reichiana Cláudia Rodrigues para escreverem o Prefácio.

A Editora Luas é uma editora feminista que iniciou sua produção em 2019 e anunciou neste livro: "O movimento atual das mulheres é este: olhe para si mesma e se conheça. Informese, observe-se e compartilhe. Que assim seja" (EDITORA LUAS, 2020, p. 11). A chegada do livro no Brasil é um bom sinal, muitas discussões estão vindo à tona no que tange às questões do parto humanizado, momento no qual as mulheres assumem o protagonismo dos partos, em que há o 
crescimento e a retomada do trabalho das doulas, os avanços na área da saúde das mulheres e em temas afins, tais como o dos métodos não farmacológicos para fortalecimento do útero na preparação para o parto.

Os feminismos estão a cada dia se ocupando mais do processo do nascer e do gerar e, neste sentido, buscando apontar os prejuízos causados após longos anos de partos induzidos e na compreensão das nuances da corporeidade das mulheres, é nesta perspectiva que Casilda Rodrigáñez Bustos (2020, p. 23) anuncia o objetivo do livro como parte do entendimento do dispositivo de abertura do útero como um processo de excitação e de orgasmo.

A palavra uterina foi, muitas vezes, utilizada para desqualificar as mulheres ou nomeálas como histéricas. A histeria teve origem na palavra grega hystéra, que quer dizer útero e foi utilizada por Hipócrates para pensar uma suposta perturbação do útero que causaria uma irregularidade cerebral, tendo em vista o movimento vascular no qual o sangue iria deste órgão para o cérebro. No final do século XIX e início do XX, aconteceu a construção da histeria como fato científico e a psiquiatrização do comportamento feminino. O renomado Hospital Psiquiátrico Pitié-Salpêtrière consolidou-se em uma fábrica de transformar mulheres em histéricas, o mestre de obra era então o conhecido médico francês Jean-Martin Charcot (1825 -1893). Em seu trabalho, ele aceitava somente mulheres com suspeita de histeria e desenvolveu, durante muitos anos, pesquisas com as suas cobaias, retomando uma terminologia que chamou a atenção de Sigmund Freud, que anos mais tarde escreveu Estudos sobre a histeria (1895).

Na contramão do ideário do útero débil e contraído, o médico e cientista Wilheim Reich (1897- 1957) analisou as tensões corporais em resposta aos eventos sociais conturbados e, como contraponto, propõe a relação da expansão orgástica dos corpos. Sobre a proposta dele, Casilda Rodrigáñez Bustos (2020, p. 45) escreveu: "como diz Reich, existe uma grande diferença entre ser geradas/os no útero distendido, dentro do corpo relaxado pelo prazer, e ser geradas/os em um útero contraído, dentro de um corpo encouraçado". Utilizando-se das teorias reichianas e com base nos estudos dos obstetras Leboyer e Read, ela defende a tese de que o prazer orgástico do parto foi negado e repelido pelo patriarcado como uma forma de controle sobre os corpos das mulheres. Em sua análise feminista, o parto deve reassumir a função orgânica do prazer e recusar o papel de sofredora imposto, sobretudo, pelo mito cristão do "parirás com dor". Para ela: "a socialização patriarcal exige que a pessoa seja criada em um estado de necessidade e de medo" (RODRIGÁÑEZ BUSTOS, 2020, p. 101). É, portanto, papel das mulheres e das feministas fazer frente ao parto com dor e exercitar o útero para o prazer orgástico.

Rosamaria Carneiro (2011) defendeu a tese de doutorado na Unicamp intitulada: Cenas do parto e políticas do corpo = uma etnografia de práticas femininas de parto humanizado. Em suas análises, a partir de encontros com as mulheres envolvidas nos grupos de apoio sobre o parto humanizado, ela se surpreendeu com o fato de a maioria das mulheres acreditar que a conquista deste modo de parir não está relacionada ao feminismo.

Nos anos 1960, os feminismos causaram uma grande mudança social ao exigirem o direito ao prazer, discutirem a libertação sexual, os direitos reprodutivos e, inclusive, questionarem a obrigatoriedade da maternidade. Muitas dessas conquistas, bem como a do parto humanizado, são fruto de longas discussões, estudos e mobilizações feministas, que, para Carneiro, são sistematicamente negadas pelas mulheres, como no caso dos achados da sua pesquisa, pelo impacto do anti-feminismo, do estigma e da repulsa causada pelos movimentos feministas que questionam a imposição patriarcal sobre os corpos das mulheres. A Agência Nacional de Saúde Suplementar, em ação conjunta com o Ministério da Saúde, publicou a Resolução Normativa $368 / 2015$ que objetivou estimular o parto normal, graças ao esforço de muitas frentes de feministas ativistas da maternidade, o que colabora para o entendimento da importância dos movimentos de mulheres e de feministas.

No Congresso Internacional Ecologia do Parto e do Nascimento, realizado no Rio de Janeiro e em Santa Catarina no ano de 2002, esteve presente a antropóloga Robbie Davis-Floyd, norte-americana que foi entrevistada por Carmen Tornquist (2002, p. 396) e que afirmou "quanto mais as feministas argumentam, mais espaços estão sendo abertos, mais opções para parir uma vida". Para ela, as feministas foram peça-chave para o desenvolvimento da Antropologia nos Estados Unidos.

Tanto a pesquisadora brasileira como a norte-americana nos fazem pensar sobre a importância e o protagonismo de Casilda Rodrigáñez Bustos na produção teórica sobre o parto com prazer. O livro nos convida a pensar sobre o prazer, sobre as pulsações uterinas e sobre novas possibilidades de parir e de gerar a vida. Sejamos uterinas com prazer, como nos propõe Casilda.

\section{Referências}

RODRIGÁÑEZ BUSTOS, Casilda. Pariremos com prazer. Trad. de Caroline Caires Coelho. Belo Horizonte: Editora Luas, 2020. 
CARNEIRO, Rosamaria Giatti. Cenas do parto e políticas do corpo = uma etnografia de práticas femininas de parto humanizado. 2011. Tese (Doutorado em Ciências Sociais) - Programa de Doutorado em Ciências Sociais, Universidade Estadual de Campinas, Campinas, 341p., 2011.

EDITORA LUAS. "Nota". In: RODRIGÁÑEZ BUSTOS, Casilda. Pariremos com prazer. Trad. de Caroline Caires Coelho. Belo Horizonte: Editora Luas, 2020, p. 11.

TORNQUIST, Carmen Susana. "Humanização do Parto: entrevista com Robbie Davis-Floyd". Revista Estudos Feministas. Florianópolis, v. 10, n. 2, p. 389-397, 2002.

Patrícia Lessa (plsantos@uem.br) nasceu em Pelotas, no Rio Grande do Sul. Educadora feminista, ecovegana que cultiva árvores. Escreve e organiza livros acadêmicos e didáticos. Atua no ensino universitário presencial e a distância, informal e popular. Graduada em Educação Física e História. Doutora em História. Livros recentes: Amor \& Libertação em Maria Lacerda de Moura, publicado pela Editora Entremares (2020), O Resgate do Touro Vermelho, pela Editora Luas (2021) e Chanacomchana e outras narrativas lesbianas em Pindorama, pela Editora Luas (2021).

\section{COMO CITAR ESTE ARTIGO DE ACORDO COM AS NORMAS DA REVISTA}

LESSA, Patrícia. "Uterinas com prazer". Revista Estudos Feministas, Florianópolis, v. 30, n. 1, e82730, 2022.

\section{CONTRIBUIÇĀO DE AUTORIA}

Não se aplica.

\section{FINANCIAMENTO}

Não se aplica.

\section{CONSENTIMENTO DE USO DE IMAGEM}

Não se aplica.

\section{APROVAÇĀO DE COMITÊ DE ÉTICA EM PESQUISA}

Não se aplica.

\section{CONFLITO DE INTERESSES}

Não se aplica

\section{LICENÇA DE USO}

Este artigo está licenciado sob a Licença Creative Commons CC-BY 4.0 International. Com essa licença você pode compartilhar, adaptar, criar para qualquer fim, desde que atribua a autoria da obra.

\section{HISTÓRICO}

